\title{
CASE REPORT OF SUCCESSFUL RESUSCITATION OF A CASE OF SUICIDAL HANGING
}

Yanki D Shipmoํ.

1. Associate Professor, Department of Anaesthesiology, Central Referal Hospital, Sikkim Manipal Institute of Medical Sciences Tadong Gangtok, Sikkim

\section{CORRESPONDING AUTHOR:}

Dr. Yanki D. Shipmo.

Central Referral Hospital, SMIMS,

$5^{\text {th }}$ Mile, Tadong

Gangtok, Sikkim.

E-mail: ydshipmo2@yahoo.com

ABSTRACT: In Sikkim, the rate of suicide has been on the rise since the last 10 years. Suicidal hanging as method of ending life is a major concern among school children. It is very rare that the victims are brought on time for successful resuscitation in Sikkim. Suicide by hanging is probably the most easy way to go about taking one's own life, as the means to do it are easily available and uncomplicated and, brutally efficient in most cases. This is a case report of a young female who was brought to the emergency room of our hospital as a case of suicidal hanging. On admission her GCS was 6; she was unconscious with deteriorating vital parameters and the breathing was laboured with SpO2 of $40 \%$ in room air. Early intervention with intubation with ventilatory and circulatory support was given and she walked home after 7 days without any neurological deficit.

KEY WORDS: Near hanging suicide, early intervention

INTRODUCTION: In a study published in The Lancet in June 2012, the estimated number of suicides in India in 2010 was about 187,000 (1). A 2008 review of 56 countries based on World Health Organization mortality data found that hanging was the most common method in most of the countries (2). However, in spite of suicide by hanging being a prominent cause of suicidal deaths in India, there are hardly any statistics available on its epidemiology (3). Similarly, the rate of suicides in Sikkim is on the rise and hanging is the most common means to end one's life but there are again no statistics available. Currently, the ligature points are trees and it is of special concern because even children in their early teens are using this method and the fact that the necessary weapons are as close as the attacker's own hands makes it so easy. The act doesn't require much knowledge to accomplish and can even be carried out by people with limited physical abilities.

For the purpose of hanging, a ligature has to be tied around the neck as a noose, the body is then suspended, which tightens the ligature around the neck. Various materials can be used as an improvised noose e.g. a rope, a bed-sheet, wires, scarf, dupatta , ropes etc. The increase in suicidal hanging is of concern for two reasons; first, hanging is a lethal method with an estimated fatality rate of about $70 \%(2,4)$, second, hanging poses a challenge to current suicide prevention strategies especially in prisons /psychiatric institutions $(4,5)$. For the compression of the large vessels in the neck and the trachea, following are said to be the pressures required to do the fatal damage; It is 
said that about 2.3 -3 $\mathrm{kg}$ of pressure is required to compress the carotid artery; $2 \mathrm{~kg}$ for the jugular veins; and at least $15 \mathrm{~kg}$ for the tracheal compression ( 6 ). The amount of time it takes to lose consciousness and die is difficult to predict accurately and depends on several factors. Hanging usually results in cerebral hypoxia and decreased muscle tone around the neck. Treatment is directed toward ensuring cerebral oxygenation, lowering increased intracranial pressure, and treating respiratory distress. Prognostically good results could be achieved, if such victims are vigorously and promptly resuscitated, irrespective of their initial presentation $(3,7,8)$. Nearhanging refers to patients not killed by the act (9).

CASE REPORT:A 24 year old young woman was brought to the emergency room of our hospital as a case of suicidal hanging. She was brought in an altered state of consciousness, her glasgow coma scale (GCS) score was 6 . There was a transverse ligature mark across the neck; no subcutaneous emphysema was seen nor was any crepitus palpated, excluding any injury to the larynx and the trachea. Her BP was not recordable; pulse was feeble; breathing was laboured and arterial oxygen (Sp02) saturation was $45 \%$ in room air ; her pupils were bilaterally dilated and sluggishly reacting to light. There were no signs of any petechial haemorrhage. On auscultation, there were scattered bilateral crepitations. After securing intravenous access, the patient was sedated with propofol $1 \mathrm{mg} / \mathrm{kg}$ body weight and suxamethonium $1.5 \mathrm{mg} / \mathrm{kg}$ was used to intubate the trachea with $7 \mathrm{~mm}$ cuffed endotracheal tube with the use of McCoy laryngoscope, taking care to immobile the cervical spine by placing 2 wooden blocks on either side of the neck. Ventilation was assisted with 100\% Oxygen. She was then transferred to the ICU where she was provided with assisted ventilation with a tidal volume of $7 \mathrm{ml} / \mathrm{kg}$, respiratory rate of $12 /$ minute and inspired fraction of oxygen $\left(\mathrm{FiO}_{2}\right)$ 1 which raised the arterial oxygen saturation to $70 \%$. Head-end of bed was kept elevated to improve the venous drainage and, ventilation was adjusted in order to maintain normocarbia. She was maintained on midazolam and vecuronium infusion for sedation and muscle relaxation respectively. Blood samples were sent for routine biochemical and haematological investigations . The other management procedures included prophylactic antibiotics, dopamine infusion at the rate of 5 micrograms $/ \mathrm{kg} / \mathrm{min}$, along with $4 \mathrm{mg}$ dexamethasone 8 hourly, to counteract any rise in (intra cranial pressure)ICP. After the bladder was catheterised, it was found that there was no urine flow and this was 6 hours after she was discovered hanging. The intravenous fluid rate was increased in order to hydrate her adequately. Her blood work-up reports were found to be within normal limits. After 48 hours, there was no change in her state of consciousness and her vital parameters were not stabilising, blood pressure was recorded at $76 / 40 \mathrm{mmHg}$, pulse was still feeble and extremities were cold to touch. She was maintained with the same management but her dopamine infusion was increased to 10 microgram $/ \mathrm{kg} / \mathrm{min}$ and the intravenous fluid volume was increased and speeded up in order to hydrate sufficiently. After 72 hours, she seemed to be coming round, responding to verbal commands and there was improvement of her vitals parameters, so it was decided to taper off the dopamine infusion and start the weaning process. She was extubated and connected to 5 litres of Oxygen by polymask. She was breathing on her own without suffering any respiratory distress. Her Sp02 became stabilised around 92\%, NIBP was 85/46 $\mathrm{mmHg}$, Respiratory rate was 19/min and she was comfortable.

On the $4^{\text {th }}$ day, oxygen supplement was withdrawn and her SpO2 was $98 \%$ on room air and her NIBP also became stabilised to $96 / 58 \mathrm{mmHg}$. By then she was fully conscious, responding and, 


\section{CASE REPORT}

orientated. She was maintained only on clear fluids as a precaution as she was still a little sore in the throat.

From $5^{\text {th }}$ day, she was put on semisolid diet Subsequently consultations were sent for Ophthalmology, ENT and Forensic medicine (FMT) .

ENT consultation revealed -marked congestion near posterior commissure of the Vocal cords and the tracheal rings were intact but there still was some blood tinged sputum.

FMT report mentioned "Ligature mark $25 \mathrm{~cm}$ long and $3 \mathrm{~cm}$ width, lying obliquely in front of the neck, around the thyroid cartilage, from $4 \mathrm{~cm}$ below the right mastoid prominence to $7 \mathrm{~cm}$ below the left mastoid prominence with non-continuity at the back of the neck ( knot??)"..

She was later sent for psychiatric consultation and counseling.

Since everything seemed optimized and all consultations cleared, she was discharged and went home on the $7^{\text {th }}$ day with only a slight pain in the neck to show what she went through and how she survived the ordeal.

DISCUSSION: Effects of hanging depends on the distance of fall. In judicial hanging, the fall is greater than the body height and the injury involved is cervical fracture/spinal cord transaction leading to death (8). In cases of near hanging the fall to the ground is less than the body height and the injuries involved are usually because of strangulation(8), compression of the carotid arteries, compression of the jugular veins and compression of the airway (11). There is a difference of opinion regarding the care for cervical injuries because spine injuries have not been reported in near hanging cases $(7,8)$; however, in our scenario, we preferred to take care to prevent further morbidity.

Venous and arterial compressions along with asphyxia, seem to be the causative reasons for death in attempted suicidal hanging (11). Just $2 \mathrm{kgs}$ of compression of the Jugular veins can bring about cerebral hypoxia, resulting in loss of consciousness. The carotid artery carries much of the blood to your brain, which uses around 15\% of the entire blood supply of your body. Anything which interrupts that blood-flow for more than a few seconds will cause loss of consciousness (1). Hanging usually results in cerebral hypoxia and decreased muscle tone around the neck causing respiratory obstruction. In such cases, treatment is directed toward ensuring cerebral oxygenation, lowering increased intracranial pressure, and treating respiratory distress.

In our patient, the fact that there was no loss of time in bringing her to the hospital and that her father-in-law's immediate act of preventing a complete drop from the suspension noose , helped in a better outcome for her. Subsequently, the timely and vigorous efforts at resuscitation at the hospital resulted in that the victim walked home without any neurological deficit. Although neurological injury determines outcome following hanging, initial neurological presentation is of limited prognostic value: a poor initial condition does not exclude a good recovery $(9,10)$.

Consequently she was discharged and went home on the 7 th day with only a slight pain in the neck to show what she went though and how she survived the ordeal. Airway injuries severe enough to interfere with airway management are uncommon after attempted suicide by hanging (6). Irrespective of the initial neurological assessment, aggressive and early resuscitation to optimize cerebral oxygenation is recommended $(9,10)$. Therefore, resuscitative methods should be tried in all the victims of attempted hanging (6). For whatever the reason, we find that in Sikkim, the 
number of successful resuscitation of near hanging is not very promising. Our patient's outcome was a success story because, initially her father-in-law appeared to have prevented her from completing the act of hanging, secondly her immediate transfer to a hospital and finally, the aggressive and early resuscitative measures that was made available to her at the emergency room. This was a case of near hanging with a successful resuscitation because of early identification of suicidal act, timely transport to a tertiary centre and aggressive intervention and medical support.

\section{REFERENCE:}

1. Patel V, Ramasundarahettige C, Vijayakumar L, Thakur J. S., Gajalakshmi V., Gururaj G, Suraweera W, Jha P "Suicide mortality in India: A nationally representative survey". The Lancet 2012; 379 (9834): 2343. doi:10.1016/S0140-6736(12)60606-0

2. Vladeta Ajdacic-Gross, Mitchell G Weiss, Mariann Ring, Urs Hepp, Matthias Bopp, Felix Gutzwiller, Wulf Rössler. "Methods of suicide: International suicide patterns derived from the WHO mortality database". Bulletin of the World Health Organization2008; 86(9): 726-32

3. Ritika Gandhi, Neeta Taneja, Paritosh Mazumder, Near hanging: Early intervention can save lives.Indian J Anaesth 2011; 55(4):388-1.

4. Adams N. David Gunnell1 Olive Bennewith1, Keith Hawton, Sue Simkin Nav Kapur The epidemiology and prevention of suicide by hanging: a systematic review. International Journal of Epidemiology 2004;34(2):433-42

5. Lucy Biddle, Jenny Donovan, Amanda Owen-Smith, David Gunnell .Factors influencing the decision to use hanging as a method of suicide: qualitative study. The British Journal of Psychiatry 2010;197: 320-5 doi: 10.1192/bjp.bp.109.076349

6. Kodikara S.Attempted suicidal hanging: an uncomplicated recovery. Am J Forensic Med Pathol. 2012;33(4):317-8.

7. Vander Krol L, Wolfe R. The emergency department management of near-hanging victims.J Emerg Med1994; 12(3):285-92. [PubMed]

8. Howell, M A; Guly, H R. "Near hanging presenting to an accident and emergency department". J Accid Emerg Med. 1996;13(2): 135-6

9. Davidson JA. Presentation of near-hanging to an emergency department in the Northern Territory. Emerg Med (Fremantle) 2003; 15:28-31.

10. Kaki A, Crosby ET, Lui AC. Airway and respiratory management following non-lethal hanging. Can J Anaesth 1997; 44:445-50

11. Geo Stone. Suicide and Attempted Suicide Methods and Consequences. Chapter 23 HangingandStrangulation.hightechchat.reocities.com/SoHo/opening/3630/part2/chap23.html 